\title{
O VOCABULÁRIO COM O QUAL NIETZSCHE DEBATE A POSSIBILIDADE DA EDUCAÇÃO ${ }^{1}$
}

Vagner da Silva (UNIR) ${ }^{2}$

vagnerdasilva@hotmail.com

Resumo: Nosso objetivo aqui é apresentar o vocabulário com o qual Nietzsche debate a possibilidade da educação, analisar os vocábulos alemães utilizados pelo filósofo, e também o contexto de sua utilização, e assim detectar até que ponto o filósofo acreditava na possibilidade da educação e o que é necessário para que esta ocorra. Para tal será necessário analisar ainda, toda uma rede conceitual na qual o debate sobre a educação se enquadra no pensamento de Nietzsche, dando ênfase a duas chaves conceituais antagônicas no pensamento do filósofo: a educação para a cultura e a educação para a civilização. Nietzsche segue certa tradição filosófica alemã que distingue civilização e cultura, tal divisão tem papel preponderante nas suas concepções acerca da educação.

Palavras-chave: Nietzsche; educação; civilização; cultura.

\section{INTRODUÇÃO}

Este trabalho necessita, para atingir seu objetivo, de um esclarecimento prévio sobre o conceito de pulsão utilizado por Nietzsche. Este é um conceito bastante complexo e que sofre interpretações bastante diversas: algumas metafísicas, outras ontológicas, e por aí vai. Apresentaremos aqui o

\footnotetext{
${ }^{1}$ Recebido: 23-09-2015/ Aceito: 09-04-2016/ Publicado on-line: 19-01-2017.

${ }^{2}$ Vagner da Silva é Professor Adjunto da Universidade Federal de Rondônia (UNIR), Porto Velho, RO, Brasil.
} 
conceito de pulsão dentro da lógica conflituosa do pensamento de Nietzsche, ou seja, tentaremos compreender as pulsões não como entes, mas como forças em conflito.Esta abordagem nos permitirá apresentar conceitos novos que favorecerão a compreensão do debate em torno da possibilidade da educação para Nietzsche, e ainda mais importante, do vocabulário com o qual o autor fala de tal possibilidade, são os conceitos de condição de nascimento, condição de vida, e condiçãa de morte.

\section{O CONCEITO DE PULSÃO}

Um ser humano é, em último caso, um conglomerado de forças em constante combate umas com as outras. Esse combate é o próprio ser das pulsões: as pulsões só existem enquanto estão em conflito umas com as outras, esta seria a definição mais simples e objetiva do conceito de pulsão no pensamento de Nietzsche, todavia para chegarmos a ela são necessárias algumas explicações preliminares.

Desde o início de sua trajetória filosófica Nietzsche se esforçou por desenvolver uma estrutura argumentativa e conceitual baseada no conflito. Percebemos este conflito já em suas primeiras obras, mesmo as anteriores a $\mathrm{O}$ nascimento da tragédia, obra que trata da dualidade conflituosa entre Apolo e Dioniso. Em Aurora: reflexões sobre os preconceitos morais o filósofo constatou que as valorações e crenças morais que sustentamos não derivam de fontes metafísicas ou extra-humanas, pelo contrário, elas são bastante humanas.Diria Nietzsche: "demasiado humanas", pois nascem de algo em nós, uma força não deliberada, uma força irracional e que opta pela vida em face de qualquer circunstância, 
mesmo do rebaixamento da vida. Mas como nomear tal descoberta?

O léxico com o qual Nietzsche nomeou esse conjunto de forças é bastante variado, em especial no período anterior a Além do bem e do mal, mas as duas palavras mais utilizadas são pulsão (Trieb), instinto (Instinkt). Embora o uso indiferenciado de termos tão distintos tenha causado problemas de interpretação, em especial o uso da palavra instinto, seria difícil e até infrutífero tentar diferenciá-los no modo como o filósofo os utilizou.

Em apenas um caso essas palavras possuem ressonância em alemão. É o caso da palavra Instinkt, cuja definição no dicionário Duden da língua alemã é:

Instinkt, der: 1. natürlicher Antrieb zu bestimmten Verhaltensweisen. 2. richtiges, untrüglichesGefühl. (1. impulso natural para certos comportamentos. 2. direito, correto, sentimento inconfundível). (DROSDOWSKI, 1988. Grifo meu).

Também o dicionário de sinônimos da editora alemã Directmedia (GÖRNER, 2003) apresenta a palavra Trieb como sinônima da palavra Instinkt. A relação contrária também se verifica, sendo Trieb apresentado como sinônimo de Instinkt. Se se analisam as principais definições de ambas, descobre-se um elemento comum que pode servir de pista para melhor compreender a utilização dessas palavras pelo filósofo.

Trieb, der: 1. starker [natürlicher] Drang zu bestimmten Handlungen. (Pulsão: 1. forte [natural] desejo de certos atos).

Instinkt, der: 1. natürlicher Antrieb zu bestimmten Verhaltensweisen. (Instinto: 1. impulso natural para certos comportamentos).(DROSDOWSKI, 1988. Tradução minha). 
Nos dois casos há acontecimentos volitivos que indicam um forte arrastamento ou inclinação não racional em direção a alguma coisa, como se uma pessoa "tomada" por um desses "sentimentos" ou "sensações" não pudesse reagir racionalmente, podendo apenas obedecer a essa solicitação nãoracional e aceder aos seus caprichos. Usou-se a palavra "volitivos", entretanto, ela também não dá conta, no pensamento nietzscheano, da amplitude do problema: as pulsões não são atos volitivos; pelo contrário, os atos volitivos são consequências das relações pulsionais no interior de um indivíduo.

Analisando os textos de Nietzsche, percebe-se que esses termos são facilmente cambiáveis, como no caso a seguir:

Os fisiólogos deveriam refletir, antes de estabelecer o impulso de autoconservação (Selbsterhaltungstrieb) como o impulso (Trieb) cardinal de um ser orgânico. Uma criatura viva quer antes de tudo dar vazão a sua força - a própria vida é vontade de poder-: a autoconservação é apenas uma das indiretas, mais frequentesconseqüencias disso. - em suma: nisso, como em tudo, cuidado com os princípios teleológicos supérfluos! - um dos quais é o impulso de autoconservação (Selbsterhaltungstrieb) (nós o devemos à inconsequência de Spinoza). Assim pede o método, que deve ser essencialmente economia de princípios. (NIETZSCHE, 1992, p. 13. Grifos meus).

É bastante claro que nas partes destacadas do texto poder-se-ia substituir pulsão (Trieb) por instinto (Instinkt) e não haveria perda de sentido, tendo-se então: "instinto de autoconservação" em vez de "impulso de autoconservação". Nesse caso, o impulso é mostrado como uma força primitiva, anterior à conservação, base da vontade de poder. Lê-se na mesma obra: "[...] na época moral da humanidade, sacrificava-se ao deus os instintos (Instinkte) mais fortes que se possuía, a própria "natureza": é esta alegria festiva que reluz 
no olhar cruel do asceta, do entusiasta "antinatural"." (Idem).

Nesse caso, substituindo a palavra "instintos" por "pulsões" tem-se a mesma compreensão do trecho citado, ou seja, que na época moral da humanidade sacrificava-se o que havia de mais forte e nãoracional no homem, o que nele era natural.

Tendo compreendido a similitude dos vocábulos com os quais o filósofo designou as pulsões, e o modo como foram utilizados, ainda precisamos tomar duas precauções metodológico-interpretativas para chegar a uma boa compreensão do conceito de pulsão, a saber:

a. Não interpretar as pulsões como substâncias, ou seja, não atribuir a elas uma existência fática, metafísica, ideal ou ontológica;

b. Dividir ou classificar as pulsões - supor, por exemplo, que há pulsões do desejo, ou pulsões do prazer etc., como fez Freud ao dividir as pulsões em pulsão de vida e pulsão de morte.

Uma das maiores dificuldades em analisar o conceito de pulsões e a constituição da teoria pulsional de Nietzsche é fugir a uma interpretação substancialista, como a de Freud, em que o conceito de pulsão inicialmente aparece ligado à energia neural (primeira tópica) e depois se volatiza na dualidade pulsão de vida/pulsão de morte, vistas e pensadas como energia (segunda tópica). Não raro encontramse ideias semelhantes nas interpretações do pensamento de Nietzsche. Tais interpretações, na tentativa de fugir de outro problema bastante real, uma interpretação metafísica 
das pulsões, acabam por tomá-las como algo substancial e entrelaçam-se na rede de que tentavam fugir.A interpretação substancialista, porém, não é o único escolho no caminho da compreensão da teoria pulsional de Nietzsche; há também a interpretação que subdivide e classifica as pulsões em grupos, a exemplo do que acontece com a teoria pulsional de Freud.

Em ambos os casos o intérprete incorre em um grande problema, que é tornar Nietzsche um metafísico, justamente o que o filósofo tentou evitar a todo custo. Tal associação de Nietzsche à metafísica tende a esvaziar o poder crítico do autor, e despotencializar todos os seus conceitos.

$\bigcirc$ que, então, são as pulsões? Independentemente da palavra que Nietzsche tenha usado para significar o conceito de pulsões, esse conceito possui um conjunto de ideias que o especifica, porém uma afirmação presente em um fragmento não publicado oferece uma ótima compreensão do que sejam:

Não resta coisa (Ding) alguma, apenas quanta dinâmicos, em uma relação de tensão com todos os outros quanta dinâmicos: sua essência está na sua relação com todos os outros quanta, em seu 'efeito' sobre eles. (NIETZSCHE, 1988, p. 259. Tradução minha).

Pensar as pulsões como quanta dinâmicos de energia é a melhor saída para o perigo representado pela interpretação substancialista e pela interpretação classificatória das pulsões, ambas fazendo a teoria das pulsões de Nietzsche redundar em uma ontologia na qual as pulsões ganham a característica de ser. Entretanto, chamar as pulsões de quanta de energia ou quanta dinâmicos de energia não seria apenas mudar o nome das pulsões e repetir o processo pelo 
qual elas são vistas como ser, ou seja, atribuir-lhes identidade, permanência e igualdade?

O risco persiste e é real, mas quando se pensa que esses quanta de energia não existem como seres reais, mas apenas enquanto estão em conflito uns com os outros, e que a partir do momento em que tal conflito cessa, cessa também seu existir, então, foge-se à possibilidade de repetir a ontologização do pensamento de Nietzsche quanto às pulsões. Elas sempre devem ser pensadas como conflito ou relação entre pulsões, como ação de umas sobre as outras, nunca apenas como pulsões: para Nietzsche não é concebível uma energia que não seja atuante.

Essa visão das pulsões como quanta de poder é reforçada por Casa Nova, quando afirma que:

Em todo acontecimento nos defrontamos com o estabelecimento de uma relação entre elementos perspectivísticos de ordenação da pluralidade de forças em jogo. Cada um destes elementos perspectivísticos encerra em si mesmo uma determinada ascensão sobre esta pluralidade de forças e uma determinada capacidade de resistir aos elementos contrários à sua vigência. $\mathrm{O}$ mundo caracteriza-se então por um embate entre princípios de composição e estes princípios não estão senão inseridos em uma relação necessária de poder uns em relação aos outros. De acordo com uma certa formulação recorrente nos cadernos nietzscheanos de 1887/88, eles são quanta de poder e se instauram em sua identidade própria a partir "do efeito que exercem e ao qual resistem". Porque o mundo é marcado originariamente por uma luta entre quanta de poder e porque se mostra em sua dimensão mais primordial enquanto uma guerra entre perspectivas detentoras de uma capacidade de domínio, temos a cada instante o despontar de uma conjuntura de poder. Esta conjuntura de poder precisa incessantemente transmutar-se em função de sempre novas composições, visto que a sua instauração não encerra de uma vez por todas a guerra [...]. (CASA NOVA, 2001, p. 43).

Desse modo, vê-se que a teoria pulsional de Nietzsche 
toma o ser humano como um conjunto caótico de pulsões em constante luta e que só momentaneamente conseguem arranjos de poder que dão à existência a aparência de permanência. As pulsões são quanta de poder em constante conflito e não são pensáveis fora do conflito: as pulsões só existem enquanto se encontram em luta. Não apenas o corpo humano é fruto dessas pulsões, mas tudo que envolve o corpo humano, inclusive a sua personalidade. Nietzsche radicalizou essa ideia quando afirmou que mesmo o sujeito nada mais é do que a consequência de toda essa luta constante, apenas uma pelinha de maçã sobre um caos constante. ${ }^{3}$

\section{VONTADE DE PODER E PULSÕES}

É a partir do conceito de pulsão que se pode chegar ao conceito de vontade de poder, e dele aos conceitos de condição de nascimento, condição de vida e condição de morte. Sabemos já que o ser humano é um conjunto caótico de pulsões em luta, a vontade de poder nada mais é do que a resultante desta luta, ou seja, a vontade de poder é o que resta da luta pulsional.

$\mathrm{Na}$ teoria nietzscheana das pulsões, tudo o que se refere às pulsões, refere-se direta ou indiretamente à sua constante luta por mais poder. Manter-se vivo é apenas uma précondição em um organismo para que busque mais poder; manter-se vivo, porém, não basta, a vontade de poder é o modo único do caos pulsional. Só há conflito entre as pul-

\footnotetext{
${ }^{3}$ A frase é de Nietzsche e originalmente se refere à cultura: "Cultura é apenas uma tênue pelinha de maçã sobre um caos incandescente” (NIETZSCHE, 1988, p. 362, tradução minha).
} 
sões porque cada uma delas busca impor-se sobre as demais, absorvê-las, subjugá-las, transformá-las em suas subalternas. Assim, a vontade de poder descreve o que para Nietzsche é o movimento da vida: crescimento e expansão incessantes em busca de mais poder.

Desde o momento em que um novo ser humano nasce, aqueles que o recebem esforçam-se, de alguma forma, por moldar nele uma personalidade e caráter, por conseguinte, uma consciência e, desse modo, possibilitam que a configuração da vontade de poder das pulsões existente neles se reproduza na criança e que o processo se expanda, assegurando cada vez mais domínios de poder para esse conjunto pulsional.

Falar do estado original das pulsões no momento em que um ser humano nasce é sempre muito difícil sem recorrer ao vocabulário tradicional da filosofia metafísica, pois este se especializou justamente em tentar mostrar o que as pessoas são. Todavia,tal vocabulário foi descartado pelo filósofo aqui em estudo. Também não se pode recorrer ao vocabulário da filosofia moderna, pois, a despeito de $\mathrm{Ni}$ etzsche usar com frequência palavras como natureza e outras mais, retiradas ao léxico da filosofia moderna, ele também nos advertiu de que "a verdadeira natureza humana - [é uma - VS] frase proibida" (NIETZSCHE, 1988, p. 235. Tradução minha). Mas por que é tão importante a condição na qual nasce o ser humano?

Quando se fala em educação e se tem como pressuposto o pensamento de Nietzsche, refere-se a um processo radical de transformação. Para saber o quanto esse processo é realmente radical, é fundamental saber o que um ser humano é ao nascer e saber o que esse processo educacional pode fa- 
zer com ele.

Para evitar esses problemas, será usada a expressão condição de nascimento para significar o estado do arranjo pulsional em um ser humano no momento de seu nascimento. A condição de nascimento refere-se ao modo como as pulsões atuam umas sobre as outras em um indivíduo da espécie humana quando nasce e passa a receber sobre si a pressão de outras organizações pulsionais de poder para moldá-lo à imagem e semelhança deles.

Não nos importa saber qual é o exato conteúdo da condição de nascimento, quais são as pulsões superiores, quais são as pulsões subalternas, ou que tipo de Eu e consciência essas pulsões desenvolverão em seu favor, nem sequer se elas o farão. Tampouco nos interessa que tipo de moral essas pulsões tomarão como interpretação do mundo. O que importa é apenas saber se isto que se é quando se nasce pode ser alterado. Será possível que os vários acontecimentos que tomam lugar na vida de um ser humano podem alterar sua condição de nascimento, ou seja, o arranjo pulsional que esta pessoa é quando nasce?

Serão utilizados outros dois conceitos correlatos à condição de nascimento: condição de morte, expressão que significará o estado do arranjo pulsional em um ser humano no momento em que ele morre, e condição de vida, significando os diversos arranjos pulsionais que tomam lugar em um mesmo corpo formando personalidades diversas, Eus diversos, consciências diversas que adotam morais diversas, tudo isso ao longo de uma única vida.

Assim é possível agora analisarmos o vocabulário empregado por Nietzsche para analisar a educação, ou, em outros termos, o vocabulário que o filósofo utilizou para 
analisar os processos de modificação pulsional que podem causar mudanças tão profundas em uma pessoa, a ponto de sua condição de morte diferir da condição de vida - única circunstância admitida por Nietzsche como educação.

\section{O VOCABULÁRIO NIETZSCHEANO PARA A EDUCAC̣ÃO}

As experiências de decadência e ascensão tipológica ${ }^{4}$ ensejam, sem dúvida alguma, experiências educacionais, nas quais a estruturação pulsional dos indivíduos é alterada, fazendo com que eles experimentem diversidade nas condições de vida. A própria experiência de vida de Nietzsche revela-se esclarecedora nesse sentido - a maneira como sua condição de vida sofreu alterações ao longo de diversas experiências: a do amor perdido e ressentido em relação a Lou-Salomé; o desengano com o renascimento artístico alemão por meio do drama musical wagneriano; a profunda vivência de condições enfermiças em si mesmo. Todos esses elementos foram diversificando as condições de vida de Nietzsche de tal modo que ao morrer sua condição de morte realmente distinguia-se totalmente da condição de nascimento. Todavia, a experiência escolar propriamente dita pouco pôde fazer no sentido de promover essa real educação, o que Nietzsche relata claramente em dois textos da juventude sobre a educação, Schopenhauer como educador e, em

\footnotetext{
${ }^{4}$ Entendemos por decadência e ascensão tipológica a possibilidade de variação no tipo humano que alguém é. Nietzsche desenvolveu diversas figuras tipológicas no seu pensamento, classificando-as, a rigor, como tipos superiores e inferiores. Entendemos esta distinção como meramente quantitativa, nunca qualitativa, ou seja, o que torna o tipo superior superior, e o inferior inferior, é a intensidade de sua organização pulsional, e tal intensidade pode variar, quando aumenta, temse então o fenômeno de ascensão tipológica, quando diminui, tem-se a decadência.
} 
especial,Conferências sobre o futuro de nossos estabelecimentos de ensino, textos nos quais o filósofo comentou a impossibilidade de a escola formar o gênio.

É sabido que Nietzsche acreditava na educação, embora a considerasse um processo bastante raro, chegando a afirmar que na tentativa de modificar outras pessoas acaba-se modificado por elas (conf. NIETZSCHE, 2001, p. 214).A educação é rara porque toda configuração pulsional dominante esforça-se por prolongar o seu domínio, mantendo sua vontade de poder intacta em face das outras pulsões. A condição de nascimento de um indivíduo, a rigor, repete um processo de estruturação pulsional que lhe é anterior, a organização pulsional de seus pais, ${ }^{5}$ que tentam, desde cedo, impor-lhe um arranjo pulsional que lhes seja semelhante, o que é, também, vontade de poder, pois o que tentam as pulsões que constituem os pais é moldar o filho à sua imagem e semelhança, embora aí surja também um conflito pulsional entre os pais. ${ }^{6}$

Para além da vontade de poder dos pais, que tenta se moldar nos filhos, há ainda outra vontade de poder, uma vontade de poder social, que organiza a sociedade, suas instituições e seus membros a partir de um modelo pulsional

\footnotetext{
${ }^{5}$ Nietzsche usou com frequência o termo herança (Vererbung) para referir-se a conjuntos de caracteres transferidos através das gerações. Para o filósofo, porém, esses caracteres não se limitam aos biológicos; hábitos, crenças etc., fazem parte dele. É o que se percebe pelo seguinte trecho de Além do bem e do mal: "Não se pode extinguir da alma de um homem o que seus ancestrais fizeram com o maior prazer e constância [...]. Não é possível que um homem não tenha no corpo as características e predileções de seus pais e ancestrais: mesmo que as evidências afirmem o contrário." (NIETZSCHE, 1992, p. 180).

${ }^{6}$ Aqui, claro, foi tomado como exemplo uma família nuclear tradicional, na qual há pais presentes, modelo que diminui no Brasil, mas isso não tira a força do exemplo, pois é possível supor outros modelos de "família", desde abrigos institucionais até a orfandade e vida nas ruas. Em todo caso, estando o ser humano sujeito a outros seres humanos, estes tentarão imprimir naquele sua vontade de poder.
} 
comum. Para Nietzsche, no mundo moderno esse modelo pulsional comum é, claramente, o da decadência pulsional, o modelo dos tipos inferiores. Esse modelo de organização pulsional, que visa se preservar mais que se expandir, ${ }^{7}$ é o que se instaurou com as revoluções burguesas e que ganhou força com as políticas democráticas; é esse modelo, pois, que organiza a sociedade, que está presente em todo o sistema escolar, das creches às universidades, e que pressiona, ao longo de mais de vinte anos, todos os indivíduos, para que neles o arranjo pulsional seja como o dos demais, para que, desse modo, em cada um deles, pulsões diferentes não tentem se rebelar, ameaçando o poder das pulsões tradicionalmente em comando naquela pessoa e em toda a sociedade.

Seguindo Foucault, seria possível traçar uma longa genealogia pulsional de diversas outras instituições sociais que trabalham na perspectiva de manter a mesmice pulsional, impedindo o surgimento de novos arranjos pulsionais que ameacem a vontade de poder do grupo pulsional dominante. ${ }^{8}$ Todavia, tal análise, apesar de sua importância, não cabe neste trabalho. Essas instituições são a explicação para que Nietzsche, principalmente em suas obras da juventude, insistisse tanto na dificuldade, quase impossibilidade, de

\footnotetext{
${ }^{7}$ Para Nietzsche, a vontade de poder que visa à preservação e não à expansão é já uma vontade de poder enfraquecida e que dá testemunho de um conjunto pulsional dominante que se encontra em decadência face às pulsões que comanda.

${ }^{8}$ Novamente aqui depara-se com o problema da linguagem, de sempre se atribuir aos arranjos pulsionais uma intencionalidade por meio de uma linguagem estratégica; então, não é muito repetir que as pulsões não possuem volição no sentido tradicional do termo, as pulsões não podem querer ou deixar de querer, seu movimento é sempre em direção ao poder; e mesmo as pulsões decadentes, aquelas que buscam mais a conservação que a expansão, encontram-se em estágio de preparação para retomar sua expansão.
} 
que a escola criasse o gênio, recaindo na ideia de que o gênio precisa ser protegido e cultivado individualmente, $\mathrm{o}$ que a escola não se propõe a fazer, até pelo contrário.

Essa ideia, nos períodos seguintes da filosofia de Nietzsche, tornou-se ambígua, pois ao passo que os tipos superiores precisam de proteção, precisam também da luta tanto com outros tipos superiores quanto com os tipos inferiores, para que não sucumbam a estes. No período final de produção filosófica de Nietzsche, além do clamor de que é necessário defender os tipos superiores dos inferiores e suas instituições, ao mesmo tempo em que é necessário que aqueles superem estes, encontra-se uma distinção fundamental para a compreensão da dificuldade de se educar o ser humano, ou seja, de promover uma mudança nos seus arranjos pulsionais; tal distinção é aquela que Nietzsche realizou entre civilização e cultura.

Grosso modo, pode-se dizer que a civilização é um processo de repetição pulsional, no qual conjuntos pulsionais dominantes, em indivíduos, organizações etc., esforçam-se para que não haja alterações nos arranjos pulsionais, esforçam-se para que a condição de morte repita a condição de nascimento. Cultura, por sua vez, é o processo de desregramento pulsional capaz de promover a educação, ou seja, capaz de produzir a diferença entre condição de nascimento e condição de morte. Pode-se mesmo falar de uma cultura superior e uma cultura inferior, ambas promotoras de educação, ao lado da civilização, que representaria a impossibilidade da educação.

Ao lado dos problemas tipológicos, e conjuntamente com o problema da ascensão e decadência dos tipos, há outro ponto que requer esclarecimentos no que diz respeito 
ao problema educacional em Nietzsche, em especial quando o problema da decadência pulsional toca o da decadência social, imbricando-se em uma aparente cadeia causal na qual indivíduos impuseram ao caos uma semelhança e regularidade intensa, moldando nele uma imagem de suas próprias vontades de poder, formando, assim, as sociedades à sua imagem e semelhança e tornando-a, como se disse, um instrumento de repetição dessa estruturação interna. Esse problema ao qual se faz referência é o da cultura e civilização.

\subsection{FORMAÇÃO, EDUCAÇÃO, CIVILIZAÇÃO E} ADESTRAMENTO

No emaranhado conceitual de Nietzsche, encontram-se dois grupos linguísticos distintos quanto à possibilidade das mudanças pulsionais, o grupo linguístico cuja chave é a ideia de civilização e o grupo linguístico cuja chave é a ideia de cultura.

Na cultura, o que se tem é a possibilidade da educação, tanto a educação superior quanto a inferior, ou seja, aquele conjunto linguístico que compreende a possibilidade da ascensão e da decadência ${ }^{9}$; e, paralelo a este, flertando, mas não se misturando a ele, o conjunto linguístico que fala da impossibilidade da educação, ou melhor, da tentativa de barrá-la.

Este duplo grupo linguístico traz como palavras emble-

\footnotetext{
${ }^{9}$ É importante salientar que se a educação, para Nietzsche, consiste na mudança pulsional, ela também se dá em dois registros diferentes, há educação na decadência pulsional, e também na ascensão, pois nos dois casos há diversificação entre a condição de nascimento e a condição de vida.
} 
máticas os vocábulos alemães Erziehung e Bildung, ambos comumente traduzidos para o português como educação, embora a segunda admita também a tradução "formação". O dicionário de sinônimos Directmedia (GÖRNER, 2003) apresenta ambas como sinônimas, o mesmo se dá com o dicionário Duden, mas, mesmo as duas palavras sendo comumente cambiáveis e traduzíveis como educação, Bildung possui um espectro semântico mais vasto. A palavra é formada pelo verbo bilden, que possui um sentido muito amplo, mas sempre associado à ideia de organização, formação e enquadramento. Este último termo é similar ao substantivo neutro Bilden (das), que é definido como "representação sobre uma superfície" (tradução minha) e também pode ser usado para definir objetos artísticos como quadros e fotos, nos quais está presente a ideia de enquadrar, dar forma.

A tradição filosófica alemã sempre teve grande apreço pela palavra Bildung (que doravante aparecerá no texto apenas como formação), em especial por sua ideia de modelagem. Nietzsche não escapou a tal tradição, pelo menos não no período inicial de sua obra, marcado pela III Consideração extemporânea: Schopenhauer como educador (Erzieher), e também por uma série de conferências intituladas Sobre o futuro de nossos estabelecimentos de ensino (Bildungsanstalten).

A palavra formação está presente ao longo de todo o período de produção filosófica de Nietzsche. Seu uso, contudo, diminui no período intermediário e torna-se quase raro no período final de sua obra, momento em que o filósofo deu preferência ao termo Erziehung (que doravante aparecerá no texto apenas como educação), algumas vezes opondo-o à cultura ou a um tipo específico de cultura. Esse tipo específico de cultura é aquela que impede o surgimen- 
to dos tipos superiores, a cultura dominante de uma época, que Nietzsche mais comumente denominou como civilização (Zivilisation).

Formação, educação e civilização estão presas a uma ideia comum para Nietzsche, que é a impossibilidade da educação, o esforço social para que não surjam homens diferenciados; nem diferenciados em ascensão, nem diferenciados em decadência. A esse conjunto linguístico (formação, educação e civilização) soma-se a domesticação (Zähmung).

O termo domesticação, retirado diretamente do vocabulário dos tratadores de animais, dá-nos uma ideia de como Nietzsche pensava a educação, pelo menos a educação que ele conhecia. Para o filósofo de Zaratustra, formação, educação e civilização nada mais são do que processos de domesticação do ser humano, processos por meio dos quais o homem é tornado manso, incapaz de ferir ou de atacar.

A palavra Zähmung também pode ser traduzida como adestramento, reforçando ainda mais a noção de educação como processo no qual o ser humano é tornado dócil e cordato, disposto à obediência irrestrita, processo descrito detalhadamente em toda a segunda dissertação de A genealogia da moral. Todavia, para Nietzsche, isso está longe de ser o que ele queria da educação, que deveria ser uma estufa para plantas raras.

Com este conjunto de palavras (formação, educação, civilização e domesticação), Nietzsche quis indicar um processo de congelamento pulsional no qual o serhumano permanece sempre o mesmo, impedindo o nascimento da diferença, seja ela ascendente, seja decadente. Afinal, se na tipologia de Nietzsche há tipos superiores e inferiores, há 
também subtipos dessa inferioridade e superioridade, como o filósofo afirmou em fragmento póstumo:

Eis o que ensino: o rebanho busca perpetuar um tipo e se defende dos dois lados: contra os que degeneram dele (criminosos etc.) e contra os que o excedem. $\mathrm{O}$ rebanho tende à paralisia e à conservação, nele não há nada criativo. (NIETZSCHE, 2008, p. 165).

Tem-se, então, uma definição nietzscheana da educação na chave do conceito de civilização: um esforço constante do rebanho para que não haja ascensão ou decadência pulsional em relação a ele, uma total paralisia pulsional que impeça a mudança tipológica. Nietzsche a este respeito foi ainda mais claro em $\mathrm{O}$ crepúsculo dos ídolos, utilizando o jogo de palavras que para ele indica essa paralisia pulsional:

Tanto o amansamento (Zähmung) da besta homem como o cultivo (Züchtung) de uma determinada espécie de homem foram chamados de "melhora": somente esses termos zoológicos exprimem realidades - realidades, é certo, das quais o típico "melhorador", o sacerdote, nada sabe - nada quer saber [...]. Chamar a domesticação (Zähmung) de um animal sua "melhora" é, a nossos ouvidos, quase uma piada. Quem sabe o que acontece nas ménageries duvida que a besta seja ali "melhorada". Ela é enfraquecida, tornada menos nociva; mediante o depressivo afeto do medo, mediante dor, fome, feridas, ela se torna uma besta doentia. - Não é diferente com o homem domado, que o sacerdote "melhorou". (NIETZSCHE, 2006, p.50).

Se o esforço social em torno da educação ou formação consiste em um processo de amansamento do animal homem, Dumur equivocou-se ao afirmar que cultura (Kultur) e formação (Bildung) não podem existir separadamente:

Cultura (Kultur) e formação (Bildung) não podem existir separadamente; cada civilização inclui uma verdadeira cultura paralela à sua formação (Bildung). É verdade que Nietzsche não especifica se a cultura pode existir sem formação (Bildung). Mas muitas vezes ele men- 
ciona que formação (Bildung) pode se desenvolver sem produzir uma cultura. (DUMUR, 2009, p. 276-7. Tradução minha).

No pensamento de Nietzsche, cultura e formação não estão presas ao mesmo esquema conceitual, pelo contrário, encontram-se em esquemas conceituais distintos e contrários. Para Nietzsche, o esforço da educação ou da formação é o de impedir qualquer transformação pulsional, seja decadência, seja ascendência, ao passo que a cultura é justamente o contrário, o esforço pela mobilidade pulsional, que pode ser traduzido em criações sociais a partir de uma vontade de poder atuante. E quando Dumur afirma que para Nietzsche é possível haver formação sem que esta produza cultura, ele está sendo contraditório, pois a formação é justamente o esforço do rebanho para impedir o surgimento da cultura. Se civilização e formação pertencem ao mesmo esquema conceitual, este esquema exclui a cultura, não é possível que ela esteja associada à formação, pois são esquemas conceituais distintos e até antagônicos, como Nietzsche afirmou em fragmento não publicado:

Os ápices da cultura e da civilização estão separados entre si: não devemos nos deixar extraviar sobre o abissal antagonismo entre cultura e civilização. Moralmente falando, os grandes momentos da cultura sempre foram tempos de corrupção; e, novamente, as épocas da voluntária e coerciva domação animal ("civilização") do homem foram tempos de intolerância para as naturezas mais espirituais e ousadas. A civilização quer outra coisa que a cultura quer: talvez algo inverso [...] (NIETZSCHE, 2002, p. 51).

Se civilização e cultura querem coisas diferentes, e a formação está inscrita no mesmo esquema conceitual de civilização, fica claro que formação não pode coexistir com cultura, pois são antagônicas. Se a cultura, nessa linguagem 
moral, é um período de corrupção, isso se dá porque a cultura é o esforço do Si (Selbst) que é cada indivíduo a fim de superar em si, e também no mundo, as vontades de poder que lhe são opostas; isso quer dizer, inclusive, superar a educação e a formação de seu tempo e de sua tradição familiar, ou seja, o que se tem é as pulsões lutando e manifestando sua vontade de poder, buscando novas formas de organização e domínio que sejam capazes de criar modificações na condição de vida. Opondo-se ao esquema conceitual da civilização, encontra-se o da cultura, aquele que pode realmente promover a educação dos indivíduos, aquela educação que promove as mudanças entre condição de nascimento e condição de morte.

\subsection{Cultura e Cultivo}

É sabido que o jovem Nietzsche afirmou que "Cultura é, acima de tudo, unidade de estilos artísticos em todas as expressões da vida de um povo" (NIETZSCHE, 1988, p. 159. Tradução minha), porém, essa ideia é claramente influenciada pela metafísica de artista do jovem Nietzsche, ideia baseada na dualidade de papéis na composição artística, dualidade exercida pelos deuses Apolo e Dionísio. Todavia, Nietzsche em seus períodos intermediário e final afastou-se dessa ideia, aparecendo nas obras desses períodos apenas citações esporádicas sobre o tema, e não mais na forma da dualidade, mas deixando claro o triunfo da ideia dionisíaca sobre a apolínea.

O substantivo feminino Kultur (doravante apenas cultura) tem um significado simples e semelhante ao do português. No dicionário Directmedia, cultura é definida como "A 
totalidade dos valores espirituais e criações materiais" (GÖRNER, 2003) e tem como sinônimos civilização (Zivilisation), formação (Bildung) e Zucht, palavra de sentido amplo que pode ser traduzida como criação, cultivo e disciplina. Definições semelhantes são encontradas no dicionário $D u$ den, onde cultura é definida como "Totalidade das criações espirituais e realizações criativas dos humanos (Menschen)" (DROSDOWSKI, 1998). Em seguida, o dicionário oferece exemplos como as expressões "as culturas da África", "A cultura dos gregos", "Um povo de alta cultura". Como sinônimos o dicionário Duden oferece formativo (Ausbildung) e criação, cultivo, disciplina (Zucht).

Esse sentido amplo da palavra cultura, chegando a ser usada como sinônimo de civilização difere bastante do sentido dado à palavra pelo jovem Nietzsche. Todavia, em seu período intermediário, o uso da palavra cultura assemelhase muito ao que se encontra nos dicionários; é o que se constata em alguns aforismos de Humano, demasiado humano I:

Microcosmo e macrocosmo da cultura. - As melhores descobertas acerca da cultura o homem faz em si mesmo, ao encontrar em si dois poderes heterogêneos que governam. Supondo que alguém viva no amor das artes plásticas ou da música e também seja tomado pelo espírito da ciência, e que considere impossível eliminar essa contradição pela destruição de um e a total liberação do outro poder: então só lhe resta fazer de si mesmo um edifício da cultura tão grande que esses dois poderes, ainda que em extremos opostos, possam nele habitar, enquanto entre eles se abrigam poderes intermediários conciliadores com força bastante para, se necessário, aplainar um conflito que surja. Mas esse edifício da cultura num indivíduo terá enorme semelhança com a construção da cultura em épocas inteiras e, por analogia, instruirá continuamente a respeito dela. Pois em toda parte onde se desenvolveu a arquitetura da cultura, foi sua tarefa obrigar à 
harmonia os poderes conflitantes, através da possante união dos outros poderes menos incompatíveis, sem oprimi-los ou acorrentá-los. (NIETZSCHE, 2000, p. 188).

$\mathrm{Na}$ citação, Nietzsche trata cultura como civilização e faz coincidir no espectro semântico da palavra cultura as criações espirituais humanas, como os dicionários definiram anteriormente. Cultura, nessa citação, abrange as criações artísticas e científicas humanas, abrange também a ideia civilizatória de fazer com que elementos antagônicos convivam harmonicamente sem perderem sua liberdade e também sem se destruírem. Aqui Nietzsche está bem distante da ideia de sua juventude, de cultura como unidade de estilos; cultura, na citação, não quer a unidade, mas a multiplicidade.

Essa ideia é complementada por um texto do mesmo período, porém da obra Aurora, onde Nietzsche fala de uma cultura de mercadores(NIETZSCHE,2004, p. 127) e lá descreve os elementos que constituem essa cultura e a tornam específica, como nas definições apresentadas, onde se viram exemplos do uso do termo cultura em "culturas da África" e "cultura dos gregos". É a partir dessa ideia que se desenvolve a noção propriamente nietzscheana de cultura, onde o substantivo sempre aparece adjetivado: cultura superior, cultura aristocrática etc.

Essa ideia nietzscheana de cultura transparece em citação anterior, em que o filósofo afirma que "Os ápices da cultura e da civilização estão separados entre si: não devemos nos deixar extraviar sobre o abissal antagonismo entre cultura e civilização". A civilização representa sempre a estabilidade pulsional, a castração pulsional, a total impossibilidade da educação como diferenciação entre condição de 
nascimento e condição de morte. Já a cultura, seja ascendente, seja descendente, pois Nietzsche sabia da existência das duas, representa a educação, ou seja, a mobilidade pulsional que permite a diversificação da condição de morte em relação à condição de nascimento.

Nietzsche associou à palavra cultura adjetivada (cultura superior etc.) outro termo alemão de grande relevância, bastante presente na obra Além do bem e do mal e de grande importância para a discussão sobre a educação em seu pensamento: é o substantivo feminino Zucht (disciplina) e seus derivados, especialmente o substantivo feminino Züchtung. Derivada do verbo züchten, a palavra tem forte conotação zoológica e botânica, significando, na maior parte das ocorrências dos dicionários utilizados, cultivo (como doravante será tratada). No dicionário Directmedia, a palavra também é indicada como sinônimo de educação (Erziehung) e aparece com formação (Bildung) e civilização (Zivilisation) como sinônimos da palavra cultura (Kultur), mas, em Nietzsche, pode-se perceber o sentido específico em que o filósofo empregou a palavra:

[...] Ensinar ao homem o futuro do homem como sua vontade, dependente de uma vontade humana, e preparar grandes empresas e tentativas globais de disciplinação (Zucht) e cultivo (Züchtung), para desse modo pôr um fim a esse pavoroso domínio do acaso e do absurdo que até o momento se chamou "história" - o absurdo do “maior número" é apenas sua última forma. (NIETZSCHE, 1992, p. 103).

Há, nessa passagem, a ideia clara de Nietzsche sobre disciplina e cultivo, os quais, para o filósofo, sempre estão juntos: cultivo significa preparação para uma cultura superior, tornar o homem capaz de controlar em si e no mundo 
os elementos dispersos e caóticos, como o filósofo afirmou alhures, aplicar regularidade ao caos, ou seja, impor a vontade de poder humana a toda a natureza e ao próprio homem como natureza.

Em última instância, o cultivo é o próprio trabalho educacional superior, que visa formar uma cultura superior, embora não se oponha à inferior diretamente, e sim à civilização, à imobilidade pulsional, óbice a todo e qualquer tipo de educação. Se cultura e cultivo participam do mesmo espectro semântico no pensamento de Nietzsche, aquele que possibilita a educação, o cultivo, tem um sentindo muito mais específico, ele se refere apenas à criação de uma cultura superior e à consequente e necessária educação para essa cultura superior.

Se na tipologia de Nietzsche tem-se com tanta frequência alusão a tipos superiores e inferiores, o cultivo é fundamental na elaboração do primeiro, porém, que não haja equívocos a este respeito: esse cultivo não é proteção e facilitação, pelo contrário, o caminho para a elevação do homem aos tipos superiores é árduo e perigoso, pois sua realização nunca é uma certeza, ao passo que seu fracasso é uma constante. Há nesse processo de ascensão e decadência dos tipos, que significa a educação na forma de mudança entre condição de nascimento e condição de morte, há, como se dizia, outro ponto que requer análise detalhada: o problema da autossuperação e da autossupressão.

São muito comuns as referências à ideia de autossuperação em Nietzsche, talvez boa parte do seu pensamento seja tida como uma filosofia da autossuperação, em especial o seu pensamento educacional sempre desperta discussões a esse respeito, mais ainda no que se refere às ideias de supe- 
ração do tipo, superação do período histórico e superação da moral. De fato, a ideia de autossuperação é de grande importância no pensamento de Nietzsche, desde que se façam as ressalvas necessárias quanto ao papel do Eu no processo de autossuperação, para que não se pense em um sujeito aos moldes cartesianos superando a si mesmo e as suas limitações.

Por ter papel assim relevante no pensamento de Nietzsche é que se deve evitar a confusão entre autossuperação e outro termo semelhante no pensamento alemão, principalmente na filosofia de Hegel, mas que no pensamento de Nietzsche não tem o mesmo sentido, que é a autossupressão.

A palavra alemã Aufhebung possui um amplo espectro semântico, dentro dos seus significados encontra-se: revogação, supressão e abolição (DROSDOWSKI, 1988). No dicionário de sinônimos Directmedia (GÖRNER, 2003) há também "suspensão, no sentido técnico do direito, significando o fim do prazo de validade de última instância”. Hegel, sobre tal palavra, afirmou:

Aqui é o lugar oportuno para recordar o duplo significado de nossa expressão alemã aufheben (superar). Por um lado, aufheben quer dizer tirar, negar; nesse sentido, por exemplo, dizemos que uma lei, uma instituição etc., são suprimidas, superadas (aufgehoben). Por outro lado, porém, aufheben significa também conservar; e, nesse sentido, dizemos que algo está bem conservado através da expressão wohlaufgehoben. Essa ambivalência do uso linguístico do termo, pelo qual a mesma palavra tem sentido negativo e positivo, não deve ser considerada casual, sequer deve-se fazer disso motivo de acusação contra a linguagem, como se fosse causa de confusão; pelo contrário, nessa ambivalência se reconhece o espírito especulativo da nossa língua, que vai além da simples alternativa 'ou-ou' própria do intelecto. (HEGEL, apud REALE, 1991, p. 109-10). 
Se a expressão Aufhebung, derivada do verbo aufheben, tornou-se com Hegel um conceito significativo no momento especulativo de sua dialética, representação da síntese do pensamento, momento em que se tem, a um só tempo, supressão e conservação, o mesmo não se pode dizer do uso que Nietzsche deu ao termo, uso apenas negativo e sem o sentido conceitual que a palavra possui no pensamento de Hegel. É isso que afirma o tradutor brasileiro Paulo César de Souza:

[...] O verbo aufheben significa primariamente "levantar, pegar (algo do chão)", e também "conservar, guardar" ou "cancelar, abolir, acabar". Com base na riqueza de sentidos do termo, Hegel o elaborou e transformou em conceito filosófico - prática comum na filosofia de língua alemã. No texto de Nietzsche, porém, Aufhebung tem claramente o significado de "supressão, cancelamento". (NIETZSCHE, 1998, p. 156).

Em Hegel, o mesmo vale para o correlato de Aufhebung, o termo Selbstaufhebung, onde a partícula selbst, o self inglês ou o si da língua portuguesa, dá o sentido tanto de autossupressão quanto de autossuperação. Em Nietzsche, porém, como anteriormente, a palavra também não tem a conotação conceitual encontrada em Hegel, o sentido é puramente negativo, é o que se percebe na segunda dissertação de $A$ genealogia da moral:

A justiça, que iniciou com "tudo é resgatável, tudo tem que ser pago", termina por fazer vista grossa e deixar escapar os insolventes termina como toda coisa boa sobre a terra, suprimindo a si mesma (selbstaufhebend). A autos-supressão da justiça (Selbstaufhebung): sabemos com que belo nome ela se apresenta - graça; ela permanece, como é óbvio, privilégio do poderoso, ou melhor, o seu "além do direito". (NIETZSCHE, 1998, p. 62). 
A confusão em torno dessa palavra e do uso que Nietzsche lhe deu (uso comum, não conceitual) acontece quando ela é confundida com outro termo bastante utilizado por Nietzsche, a palavra alemã Überwindung e seu correlato Selbstüberwindung, significando, respectivamente, superação e autossuperação, ambas com carga semântica tipicamente nietzscheana, utilizadas como conceitos, mas comumente confundidas com Aufhebung e Selbstaufhebung. É o que fez, por exemplo, Zuckert em seu texto de 1983:

A tentativa não apenas de reprimir, mas, finalmente, destruir e assim negar o instinto animal do homem, Nietzsche sugere, constitui uma tentativa de mudar a natureza humana. Como tal, a tentativa não pode ter sucesso, porque os seres humanos são fundamentalmente animais, seres vivos. Para destruir os instintos, é necessário matar a besta. Não simples negação, mas a transformação (Aufhebung) - dar nova configuração, forma e significado - da existência humana é o que é necessário. (ZUCKERT, 1983, p. 62. Tradução minha).

As palavras que a autora usou para descrever transformação (Aufhebung), "dar nova configuração, forma e significado”, não compreendem o espectro semântico que Nietzsche aplicou ao vocábulo Aufhebung, e sim ao vocábulo Überwindung, que, embora muitas vezes seja usado como sinônimo de Aufhebung, teve, todavia, uso distinto no pensamento de Nietzsche.

O substantivo feminino Überwindung deriva do verbo überwinden, tem como primeiro significado no dicionário Duden o vocábulo "derrotar" e traz como exemplo de utilização: "Ele derrotou o adversário depois de uma luta dura"; a segunda definição traz um conjunto de três palavras: lidar (bewältigen), subjugar (bezwingen) e tornar-se mestre (meistern). Curiosamente, a terceira definição não traz uma pala- 
vra, mas a descrição de uma ação: "Abandonar/superar uma resistência interior e finalmente fazer algo". No dicionário de sinônimos da editora Directmedia, encontra-se também a descrição de uma ação: "Livrar-se de um pesado fardo psicológico”. Desse modo,Überwindung, que doravante será tratado apenas como superação, é o substantivo que define o processo descrito pelo verbo superar (überwinden).

Nietzsche, porém, não estava interessado em qualquer forma de superação; embora a palavra lhe fosse bastante cara, o que mais interessava ao filósofo era a autossuperação (Selbstüberwindung), que, de acordo com Zaratustra, era abandonar o que lhe era mais caro, tornar-se adversário daquilo que ele mesmo havia criado, para poder seguir criando, nunca apegado ao que já foi, ao que já está criado, nas palavras do profeta de Nietzsche: "O que quer que eu crie e como quer que isso eu ame, - em breve deverei ser seu adversário e do meu amor: assim quer a minha vontade." (NIETZSCHE, 1988, p. 148. Tradução minha).

Nas palavras de Zaratustra, é perceptível a diferença entre autossuperação e autossupressão.Aautossupressão, pensada na dialética hegeliana, poderia ser representada graficamente por uma espiral, tendo um objetivo conhecido na forma do absoluto, nesse movimento não há perda ou negação total, mas apenas uma negação parcial, que, por não ser total, permite a manutenção do que foi aparentemente negado, na verdade absorvido, se não no todo, ao menos em suas qualidades superiores; o que foi suprimido não deixa de existir, mas passa a existir como algo inserido em um contexto maior do qual se torna função, cada figura do novo traz em si os elementos que lhe foram anteriores, mas que, dialeticamente superados e suprimidos, constitu- 
em também o novo.

A autossuperação em Nietzsche poderia ser representada por um oroboro, símbolo alquímico no qual uma serpente devora a própria cauda, formando um círculo infinito de autodestruição. A autossuperação é a negação absoluta, não manutenção do já sido, avanço constante em direção a novas criações, que implica, necessariamente, o total abandono e guerra ao passado e, ao mesmo tempo, entrega total ao devir, que no movimento cíclico do eterno retorno são uma e a mesma coisa.

Aqui o pensamento de Nietzsche obriga o estudioso a incríveis exercícios de interpretação, pois autossuperação e autossupressão, embora aparentemente contrárias, podem fazer parte de um mesmo processo.É o que afirmou Nietzsche na terceira dissertação de A genealogia da moral, \$ 27:

[...] Todas as grandes coisas perecem por obra de si mesmas, por um ato de autossupressão: assim quer a lei da vida, a lei da necessária "autossuperação" que há na essência da vida [...]. Desta maneira pereceu o cristianismo como dogma, por obra de sua própria moral; desta maneira, também o cristianismo como moral deve ainda perecer estamos no limiar deste acontecimento. (NIETZSCHE, 1998, p. 148. Grifo meu).

Pela afirmação de Nietzsche, a lei da vida, que é a lei da autossuperação, quer que haja também autossupressão, dando a entender que a autossupressão está dentro de uma lei maior ou um acontecimento maior, que é a autossuperação; porém, quando fala do cristianismo como dogma, o filósofo dá mostras de que a autossupressão à qual se refere não é a autossupressão em sentido hegeliano. Para Nietzs- 
che, o cristianismo, ao tornar a busca pela verdade seu ponto fundamental, ${ }^{10}$ condenou a si próprio, pois foi a busca pela verdade que levou o homem a finalmente constatar a inexistência de Deus.

A abolição do cristianismo e a abolição de seus dogmas são uma supressão de algo criado pelo homem, e chega o momento, como disse Zaratustra em citação anterior, de odiar e fazer guerra ao que um dia foi uma criação bem amada. Não se trata, como na dialética hegeliana, de superar a estrutura primitiva, conservando os valores superiores (dogma e moral), e sim do abandono do todo. Desse modo, a supressão do cristianismo faz parte do necessário processo de autossuperação da moral de cada indivíduo que quer tornar-se o que Nietzsche nomeou de espírito livre.

Se a destruição na forma dessa autossupressão pode resultar em autossuperação, isso não indica que sempre a destruição redundará criativa, pelo contrário, na maior parte das vezes redunda apenas em grande desperdício. Afinal, como Nietzsche tantas vezes insistiu, a natureza é pródiga em desperdícios. Esse é um motivo para que a educação, em especial seu aspecto de ascensão, seja tão rara: ela é sempre dispendiosa.

Educação (Erziehung): um sistema de meios para arruinar as exceções em proveito da regra. Formação (Bildung): um sistema de meios para dirigir o gosto contra a exceção, em proveito do mediano. Dito dessa forma, isso é rude; entretanto, economicamente considerado [é, OGJ] completamente racional. Ao menos por um longo tempo, onde uma cultura ainda se mantém em pé com esforço, e toda exceção representa uma espécie de dissipação de força (algo que desvia, se-

\footnotetext{
${ }^{10}$ Essa é uma afirmação de Nietzsche; para tal, ele se baseou no Evangelho de João 8:32: "Conhecereis a verdade e a verdade vos libertará".
} 
duz, adoece, isola). Uma cultura da exceção, da tentativa, do perigo, da Nuance - uma cultura de estufa para plantas não habituais só tem direito à existência quando está à mão força suficiente para que, daí em diante, até mesmo a dissipação se torne econômica. (NIETZSCHE, 2002, p. 50).

A citação acima é bastante rica, pois nela Nietzsche mostrou o quanto o surgimento de tipos superiores é um acontecimento raro e como a educação (na chave do conceito de civilização) tem se esforçado justamente para impedir tal acontecimento. A educação tem sido, para o filósofo, o conjunto de meios para a prevalência dos tipos inferiores sobre os tipos superiores. Sabendo que a educação e a formação (na chave do conceito de civilização) trabalham de modo a impedir uma autossuperação, ou seja, impedir a ascendência do tipo, impedir que pulsões fortalecidas assumam o domínio do conjunto, percebe-se o quanto a autossuperação é um acontecimento raro, percebe-se o quanto a ascensão tipológica não é recorrente.

Por fim, é necessário levantar ainda um último problema: ao nascer, um determinado indivíduo possui uma determinada condição de nascimento, as mais diversas experiências de vida (dores, sofrimentos, alegrias, encontros, desencontros, reencontros etc.), contudo, alteram-lhe a condição de nascimento, de modo que aos quarenta anos de idade o conjunto pulsional que ele é, em seus arranjos e hierarquias internas, tornou-se totalmente diverso daquele que era quando nasceu e que a sociedade esforçou-se por manter por meio da educação e formação (na chave do conceito de civilização); essa mesma pessoa, por meio de novas experiências reencontra e redescobre seu passado, do qual esteve afastada para que a memória, importante trunfo 
na guerra pelo controle pulsional, não enfraquecesse o novo arranjo de domínio pulsional. Todavia, esse reencontro efetiva o perigo que sempre representou, e há nesse sujeito novas transformações pulsionais, que, por fim, restauram o arranjo pulsional que era ao nascer, fazendo com que a condição de morte repita a condição de nascimento.

O que se tem nesse exemplo é uma distinção inicial entre condição de nascimento e condição de vida, mas uma repetição da condição de nascimento na condição de morte, a despeito das mudanças ao longo da condição de vida, ou seja, por fim, a condição de morte repetiu a condição de nascimento. Para Nietzsche, tal repetição não seria possível, a não ser, claro, na figura do eterno retorno do mesmo, mas não discutiremos esta questão aqui.

O filósofo de Zaratustra não admitia que um arranjo pulsional pudesse ser repetido, apenas o tipo poderia ser repetido. Se o sujeito do exemplo anterior nascesse como um tipo inferior, poderia ascender tipologicamente com as experiências da vida e tornar a decair, sem, contudo, tornarse o mesmo que era anteriormente. $O$ mesmo pode-se dizer em sentido contrário: se fosse um tipo superior, poderia decair e, convalescendo, ascender novamente a um tipo superior, mas não o mesmo indivíduo superior que tinha sido antes.

Com esse exemplo torna-se evidente o sentido da autossuperação: ela requer sempre o novo e o diverso, não admite a repetição dos arranjos pulsionais, mas sempre a criação de novos arranjos pulsionais. $O$ sujeito que se supera, independentemente do patamar tipológico no qual se encontre, cria sempre o novo, torna-se o novo. Essa autossuperação é, então, sem dúvida, o objetivo da educação (na chave do 
conceito de cultura), que é um cultivo de tipos superiores; a superioridade do tipo, mesmo quando herdada, só é mantida a custo de constantes novas autossuperações, a custo de constante conflito pulsional e mudança nos arranjos pulsionais, ou então de constantes novas conquistas das pulsões dominantes e vitoriosas. Não havendo autossuperação, o tipo degenera e decai.

\section{CONCLUSÃO}

Quando Nietzsche afirmou que nosso corpo é apenas uma estrutura social de muitas almas (NIETZSCHE, 1992, p. 25), ele quis dizer que ao longo de uma vida é possível que se viva tantas condições de existência que a condição de morte é radicalmente distinta da condição de nascimento. $\mathrm{O}$ agente que opera essa diferenciação é, inegavelmente, a vontade de poder; e a alteração dá-se em função dos constantes embates pulsionais.

No vocabulário nietzscheano, só é possível chamar de educação o processo que faça brotar, da aparente unicidade do $\mathrm{Eu}$, a multiplicidade (consciente ou inconsciente) do $\mathrm{Si}$ (Selbst), sem que, no entanto, esse Si sucumba à louca tensão das pulsões em conflito. A educação, para Nietzsche, é um dos mais duros e raros processos humanos; e também, que não haja ilusões, não é prazerosa, mas é uma tentativa irreversível da vontade de poder, que muitas vezes falha.

Muitas pessoas, em face da atual sociedade burguesa de consumo, dos homens-engrenagens-de-máquinas, terão como condição de morte a mesma condição de nascimento, sem nunca conhecerem uma condição de vida que fosse diferente. Enquanto alguns chamariam isso de equilíbrio e es- 
tabilidade, o filósofo alemão chamaria de desespero, pois nada mais triste do que a incapacidade de expandir-se para além de si, de criar-se e recriar-se continuamente, sendo sempre o mesmo e vivendo medrosamente em relação à diferença, muitas vezes caçando-a e perseguindo-a. $\mathrm{O}$ que se chama de educação na atualidade era para Nietzsche, sem dúvida, o que Exupérry(1973) nomeou como a máquina de entortar homens e que Carlos Drummond de Andrade (1983) chamou de a máquina do mundo.

Abstract: Our goal here is to present the vocabulary with which Nietzsche debates the possibility of education, analyzing the German words used by the philosopher, and also the context of its use, and thus detect the extent to which the philosopher believed in the possibility of education and what is required for this to occur. This will require further analysis, a whole conceptual network in which the debate on education fits in Nietzsche's thought, emphasizing the two opposing conceptual keys in the philosopher's thought: education for culture and education for civilization. Nietzsche follows certain German philosophical tradition that distinguishes civilization and culture, such division plays an important role in their conceptions of education.

Keywords: Nietzsche; education; civilization; culture.

\section{REFERÊNCIAS}

CASA NOVA, Marco Antônio. Interpretação enquanto princípio de constituição do mundo. In: Cadernos Nietzsche, vl. 10, p. 27-47. São Paulo: USP, 2001.

DROSDOWSKI, Günther; MÜLLER, Wolfgang; SCHOLZE-STUBENRECHT, Werner; WERMKE, Matthias. Duden: Stilwörterbuch der deutschen Sprache. Dudenverlag: Mannheim, Leipzig, Wien, Zürich: 1988.

DUMUR, Louis. Nietzsche and culture. Translated by: Erin Lamm. In: The Philosophical Forum, p. 275-286. 
New York: The Philosophical Forum, 2009.

GÖRNER, Herbert und KEMPCKE, Günter. Wörterbuch Synonyme: Neu bearbeitet und herausgegeben. Berlin: Directmedia, 2003.

NIETZSCHE, Friedrich Wilhelm. A "Grande Política", fragmentos. Introdução, seleção e tradução: Oswaldo Giacoia Jr. Campinas (SP): Departamento de Filosofia, Instituto de Filosofia e Ciências Humanas-IFCH-UNICAMP, 2002.

. A Gaia Ciência. Tradução, notas e posfácio: Paulo César de Souza. São Paulo: Companhia das Letras 2001.

- A Vontade de Poder. Tradução e notas: Marcos Sinésio Pereira Fernandes e Francisco José Dias de Moraes. Rio de Janeiro: Contraponto, 2008.

- Além do Bem e do Mal: prelúdio a uma filosofia do futuro. Tradução, notas e posfácio: Paulo César de Souza. São Paulo: Companhia das Letras 1992.

- Aurora: reflexões sobre os preconceitos morais. Tradução, notas e posfácio: Paulo César de Souza. São Paulo: Companhia das Letras 2004.

- Crepúsculo dos Ídolos, ou como se filosofa com o martelo. Tradução, notas e posfácio: Paulo César de Souza. São Paulo: Companhia das Letras 2006.

. Genealogia da Moral: uma polêmica. Tradução, notas e posfácio: Paulo César de Souza. São Paulo: Companhia das Letras, 1998.

. Humano, Demasiado Humano: um livro para espí- 
ritos livres, volume I. Tradução, notas e posfácio: Paulo César de Souza. São Paulo: Companhia das Letras 2000.

. KSA. München: Walter de Gruyter GmbH e Co. KG, Berlin, 1967-77 und 1988.

REALE, Giovanni. História da filosofia: do Romantismo até nossos dias. São Paulo: Paulus, 1991. (ColeçãoFilosofia, vl. III).

ZUCKERT, Catherine. Nietzsche on the Origin \& Development of the Distinctively Human. In: Polity, Vol. 16, No. 1. p. 48-71. Hampshire (England): Palgrave Macmillan Journals, 1983. 